\title{
0 uso da pesquisa-ação para a avaliação e 0 aprimoramento de práticas integradas para a vigilância da qualidade da água para consumo humano: potencialidades e desafios
}

\author{
The use of action research for assessment and improvement of integrated \\ practices on drinking-water quality surveillance: potentialities and challenges
}

\section{Ana Carolina Lanza Queiroz}

Enfermeira, Mestre em Saúde Pública, Doutora em Saneamento, Meio Ambiente e Recursos Hídricos pela Universidade Federal de Minas Gerais (UFMG); Professora da Pontifícia Universidade Católica de Minas Gerais (PUC-Minas) - Belo Horizonte (MG), Brasil.

\section{Laís Santos de Magalhães Cardoso}

Enfermeira, Especialista em Saúde Coletiva e Mestranda em Saneamento, Meio Ambiente e Recursos Hídricos pela UFMG, bolsista do Departamento de Engenharia Sanitária e Ambiental da UFMG - Belo Horizonte (MG), Brasil.

\section{Léo Heller}

Engenheiro Civil e Sanitarista. Doutor em Epidemiologia pela UFMG. Pós-doutor pela University of Oxford - Oxford, Reino Unido. Pesquisador do Conselho Nacional de Desenvolvimento Científico e Tecnológico (CNPq). Professor Associado do Departamento de Engenharia Sanitária e Ambiental da UFMG - Belo Horizonte (MG), Brasil.

\section{Sandy Cairncross}

Engenheiro de Saúde Pública. Doutor em Mecânica dos Solos pela University of Cambridge - Cambridge, Reino Unido. Professor da Faculty of Infectious and Tropical Diseases da London School of Hygiene \& Tropical Medicine (LSHTM) - Londres, Reino Unido.

\section{Resumo}

Este artigo apresenta as fases de uma pesquisa-ação empreendida para avaliar e aprimorar as práticas do Programa de Vigilância em Saúde Ambiental relacionada à qualidade da água para consumo humano (Vigiagua) em três municípios do estado de Minas Gerais, Brasil. Com o emprego do método qualitativo, objetivou-se detalhar os processos desencadeados durante as fases da pesquisa, problematizando-os metodologicamente e discutindo os desafios e potencialidades decorrentes da operacionalização do método. Constatou-se que a pesquisa-ação possibilitou a apropriação e o envolvimento dos sujeitos implicados na pesquisa; a criação de espaços intersetoriais, inter e intrainstitucionais; o estabelecimento de novas relações e a ampliação do conhecimento acerca do objeto trabalhado. Esses ganhos, possivelmente, transcenderão à própria pesquisa realizada.

Palavras-chave: vigilância em saúde; vigilância da qualidade da água; pesquisa-ação.

\section{Abstract}

This work presents the stages of an action research applied to assess and improve the practices of the Environmental Monitoring Program related to water quality for human consumption (Vigiagua) in three municipalities of Minas Gerais, Brazil. It aimed to detail the processes triggered during each phase of the action research, exploring methodological challenges and opportunities arisen, using a qualitative method. It was verified that the use of the action research allowed empowerment of actors involved in the research; the establishment of inter and intra-institutional and intersectoral spaces and new relationships and the expansion of the knowledge about the subject in question. These achievements will possibly transcend the research itself.

Keywords: public health surveillance; water quality monitoring; action research. 


\section{Introdução}

Lewin (1946/1948) descreve a pesquisa-ação como uma espiral de etapas, compostas por ciclos de planejamento, ação e descobertas resultantes dessa ação. Possibilita, também, a ampla e explícita interação entre o pesquisador e as pessoas envolvidas na situação investigada, resultando, de acordo com Thiollent (2008), na priorização de problemas a serem pesquisados e nas soluções a serem trabalhadas. De acordo com Engel (2000), devido à sua característica dinâmica, é possível intervir na prática de modo inovador, no decorrer do próprio processo, e "não apenas por meio de recomendações na sua etapa final, aprofundando em situações particulares, de forma interativa, repleta de ciclos de reajustes para uma reflexão e uma ação mais esclarecidas" (MORIN, 2004). No Brasil, este método vem sendo crescentemente utilizado em trabalhos que abordam questões educacionais (ABDALLA, 2005; GREENWOOD e LEVIN, 2006; MELLO; MOYSÉS; MOYSÉS, 2010; PIMENTA, 2005), ambientais (CERATI e LAZARINI, 2009; REIGADA; TOZONI REIS, 2004), de saúde coletiva (GRITTEM et al., 2009; HOGA e REBERT, 2007), empresariais e organizacionais (CHIMENDES et al., 2008; MIGUEL, 2009), entre outras.

A proposta deste artigo, de avaliação das fases de uma pesquisa-ação aplicada visando ao aprimoramento das práticas do Programa de Vigilância em Saúde Ambiental relacionada à qualidade da água para consumo humano (Vigiagua), adveio principalmente do reduzido número de artigos científicos que, apesar de utilizarem o método, raramente detalham o seu processo e o problematizam (ABDALLA, 2005; REASON, 2006). Geralmente, a literatura foca nos resultados e descreve de forma sucinta suas fases, ou o caminho trilhado pelos pesquisadores e colaboradores na condução da pesquisa, e tampouco trazem um olhar crítico sobre o processo em si. No entanto, corroboramos a afirmação de Duarte (2002) de que relatar procedimentos de pesquisa, mais do que cumprir uma formalidade, oferece a outros a possibilidade de refazer o caminho e, desse modo, avaliar com mais segurança seus achados.

Com início em outubro de 2008, e finalizada em junho de 2011, a pesquisa-ação em pauta partiu de uma demanda da Coordenação Geral de Vigilância em Saúde Ambiental (CGVAM) do Ministério da Saúde (MS) que objetivou aprimorar e fortalecer as ações de vigilância da qualidade da água para consumo humano (Vigiagua) a partir de articulações entre esse e demais departamentos que constituem a Vigilância em Saúde (Vigilância Epidemiológica principalmente) e entre os diferentes setores (Educação, Saúde, Meio Ambiente, Recursos Hídricos etc.) que compõem o escopo organizacional na instância dos municípios. A interface interdisciplinar, intersetorial e interdepartamental almejada revela-se extremamente importante no nível municipal, executor, uma vez que constitui princípio para se atingir o pleno êxito das ações de saúde, por natureza, complexas. Nesse contexto, pode-se projetar uma dupla fecundação: o campo da saúde pode fornecer dados importantes para nortear as ações prioritárias para a vigilância da qualidade da água para consumo humano em dada localidade, como dados de morbimortalidade e características da população, alimentando uma avaliação de risco, e, por sua vez, a vigilância da qualidade da água pode fornecer informações sobre potenciais perigos inerentes às diversas formas de abastecimento de água para essa população. Em síntese, partiu-se do pressuposto de que essa articulação é necessária e desejável e que sua materialização poderá ampliar a efetividade das ações, redundando em melhor saúde para a população, uma vez que poderá reduzir riscos e perigos advindos do consumo de água.

Para facilitar a avaliação e a discussão sobre cada uma das etapas da pesquisa-ação empreendida, optou-se por discuti-las por fases, com base em Thiollent (2008): exploratória, principal, de ação e de avaliação. As ações executadas em uma etapa preliminar às supracitadas envolveram reuniões e contatos com as Secretarias Estadual e Municipais de Saúde, seleção dos municípios, construção dos roteiros de entrevistas, sua aplicação em projetos-piloto e posterior adequação para aplicação nos campos selecionados. Portanto, embora esta fase preliminar componha fase estruturante do processo da pesquisa, não constituiu objetivo deste trabalho explorá-la. Cumpre ressaltar que o projeto foi aprovado pelo Comitê de Ética em Pesquisa da Universidade Federal de Minas Gerais, Parecer no 431/08.

O presente artigo apresenta as fases dessa pesquisa-ação detalhando os processos e os problematiza com a finalidade de discutir os desafios e as potencialidades de sua aplicação em pesquisas que envolvem diferentes atores, na construção conjunta de instrumentos de intervenção, visando, assim, ao aprimoramento de práticas.

\section{Percurso metodológico}

Optou-se por uma abordagem detalhada em três cenários, municípios com diferentes portes populacionais: pequeno, médio e grande, respectivamente menor que 20.000 habitantes, com população entre 20.000 e 100.000 e município com população maior que 500.000 habitantes. Entre os municípios que atenderam aos critérios previamente estipulados, como integrar a Região Metropolitana de Belo Horizonte (RMBH), possuir Estratégia Saúde da Família implantada e presença de Vigilância em Saúde Ambiental relacionada à qualidade da água para consumo humano e de Vigilância Epidemiológica atuantes. Ademais, por se constituírem, segundo a Secretaria de Saúde do Estado (SES-MG), localidades com melhor desempenho do 
Vigiagua na RMBH, foram selecionados aqueles municípios em que, após a exposição do problema e objetivos da pesquisa-ação, técnicos e gestores demonstraram interesse pela proposta e se prontificaram a participar da pesquisa. A Tabela 1 apresenta algumas características das localidades no que se refere ao porte populacional, área da unidade territorial, população, índice de desenvolvimento humano (IDH), principal atividade econômica, cobertura do Sistema de Abastecimento de Água.

$\mathrm{Na}$ tentativa de problematizar a pesquisa-ação empreendida, lançando um olhar crítico sobre o caminho percorrido, empregou-se o método qualitativo, que melhor contempla o objeto e os objetivos desta investigação. Segundo Minayo e Sanches (1993, p. 247), a investigação qualitativa vislumbra "aprofundar a complexidade de fenômenos, fatos e processos particulares e específicos de grupos". Assim, procedeu-se à análise de documentos e arquivos em audiovisual produzidos em cada fase da pesquisa-ação, a saber: entrevistas transcritas, atas de reuniões, textos transcritos de vídeo-filmagens e anotações realizadas em diário de campo pela equipe de pesquisa nas reuniões e seminários, e durante a observação participante. Estes conformaram o corpus, ou seja, constituíram-se material de análise (BAUER e AARTS, 2006, p. 44-45).

Os aspectos avaliados a partir desses elementos podem ser sintetizados nas seguintes perguntas norteadoras, as quais o presente trabalho tenciona responder e/ou discutir:

a) A pesquisa-ação favoreceu a participação e o envolvimento/compromisso dos atores participantes?;

b) Obteve-se êxito, ou seja, o objetivo primeiro de elaborar e testar procedimentos para integração entre vigilâncias visando ao aprimoramento de práticas foi atingido?

c) Quais os desafios encontrados durante a operacionalização da pesquisa-ação? E quais as potencialidades do emprego do método?

\section{0 caminho percorrido: fases da pesquisa-ação}

\section{Fase exploratória}

A fase exploratória, definida também como fase de identificação ou contextualização, teve como objetivo estabelecer um primeiro contato com a situação dos municípios participantes. Constituiu-se etapa essencial, uma vez que possibilitou identificar as formas de atuação do Vigiagua, principalmente, e também da Vigilância Epidemiológica, da Vigilância Sanitária e Zoonoses, inseridas na Vigilância em Saúde nos contextos selecionados para o trabalho, bem como conhecer os atores-chave na esfera municipal, referidos por Greenwood e Levin (2006) como colaboradores locais.

Primeiramente, foram definidos por meio de reuniões com os coordenadores da Vigilância em Saúde e, no caso dos municípios de menor porte, diretamente com os secretários de saúde, os informantes-chave - atores que integrariam o núcleo da pesquisa juntamente com os pesquisadores - constituídos, nas três localidades pesquisadas, por técnicos e coordenadores das Vigilâncias Ambiental e Epidemiológica. O perfil desses informantes-chave compreendia homens e mulheres, servidores públicos efetivados, com tempo mínimo de 5 anos e máximo de 30 anos de atuação na rede municipal de saúde, residentes no município em que trabalhavam. O nível educacional dos informantes-chave abrangia ensino médio, técnico profissionalizante e ensino superior — sendo identificadas graduações em Ciências Biológicas, Engenharia Química, Odontologia, Gestão Ambiental, Nutrição e Pedagogia especialização e mestrado (nas áreas de Gestão Ambiental, Engenharia Elétrica e Ciências Biológicas). Identificou-se que, nos municípios de médio e grande porte populacional, os profissionais atuavam exclusivamente na Vigilância em Saúde Ambiental. No município de menor porte, o técnico respondia também pelas ações de Vigilância Sanitária, na qual, diferentemente dos outros municípios, se inseria o Vigiagua.

Após encontros e reuniões informais, que permitiram o acesso dos pesquisadores ao universo dos participantes, com a finalidade de se discutir as principais questões referentes ao objeto da pesquisa, ou seja, a construção conjunta de instrumentos de trabalho que potencializariam o planejamento e a atuação integrada do Vigiagua com demais departamentos e setores, foram realizadas entrevistas com cada informante-chave identificado. Assim, por meio de um roteiro semiestruturado foram exploradas questões referentes aos bancos de dados utilizados no município e análise

Tabela 1 - Dados municipais relativos à área da unidade territorial, população, índice de desenvolvimento humano, principal atividade econômica e cobertura do Sistema de Abastecimento de Água.

\begin{tabular}{|c|c|c|c|c|c|}
\hline Porte populacional & $\begin{array}{l}\text { Área }{ }^{1} \\
\left(\mathrm{~km}^{2}\right)\end{array}$ & $\begin{array}{l}\text { População }{ }^{1} \\
\text { (habitantes) }\end{array}$ & $\mathrm{IDH}^{2}$ & $\begin{array}{l}\text { Principais atividades } \\
\text { econômicas }^{1}\end{array}$ & $\begin{array}{l}\text { Cobertura pelo Sistema de } \\
\text { Abastecimento de Água } \\
\text { (\% sede urbana })^{3}\end{array}$ \\
\hline Pequeno & $1.114,155$ & 17.134 & 0,731 & Serviços e agropecuária & 81,90 \\
\hline Médio & 429,063 & 80.998 & 0,821 & Serviços e indústria & 100 \\
\hline Grande & 195,268 & 603.442 & 0,789 & Serviços e indústria & 100 \\
\hline
\end{tabular}


de como esses dados eram tratados — nível de cobertura, nível de desagregação dos dados, formas de publicização, notificação de ocorrências, referência e contrarreferência - e transformados em informações para desencadear ações. No que se constituiu uma avaliação inicial, a análise das respostas revelou persistirem dificuldades para cadastramento e vigilância a instalações de abastecimento de água, a não realização de séries temporais, a deficiência de instrumentos de georreferenciamento e, ainda, a integração incipiente entre os diferentes departamentos e setores. Verificou-se, por exemplo, que a integração entre a prática dos profissionais do Vigiagua e da Vigilância Epidemiológica é incipiente nos três municípios, restringindo-se basicamente a situações de surto. Os resultados das entrevistas foram compilados e apresentados pelos pesquisadores aos núcleos de pesquisa constituídos em cada um dos municípios com o objetivo de possibilitar a discussão acerca das questões a serem tratadas nos seminários previstos, os potenciais participantes e os possíveis encaminhamentos e condução do pensamento do grupo, visando à programação das ações consideradas prioritárias, discussão de sua importância para o serviço, aplicabilidade e exequibilidade. Os insiders, forma como Greenwood e Levin (2006) se referem aos atores componentes dos grupos constituídos (núcleos de pesquisa), possuem um conhecimento mais abrangente e de longa data dos problemas em questão e dos contextos nos quais estes ocorrem e, além disso, sabem como e com quem buscar informações adicionais. Duarte (2002) refere-se à importância desse contato com o "ego focal", ou seja, o sujeito que dispõe de informações a respeito do segmento em estudo, capaz de "mapear" o campo de investigação, decodificar suas regras, indicar pessoas com as quais se relacionar naquele meio e sugerir formas adequadas de abordagem. Portanto, reitera-se a importância de sua identificação no início do desenvolvimento da pesquisa, por meio da indicação dos coordenadores, inserção no ambiente de trabalho que se deseja explorar e vivência com os profissionais que ali atuam.

\section{Fase principal: o planejamento da ação}

Partindo da avaliação inicial sobre a realidade dos serviços em cada uma das localidades, obtida na fase exploratória, e tendo como referência a possibilidade do planejamento integrado baseado nos dados das vigilâncias, para desencadeamento de ações intradepartamental e intersetorial, conduziu-se o seminário central em cada município. Este reuniu equipe e núcleo de pesquisa e demais atores indicados pelo núcleo, designados como colaboradores locais, implicados na construção conjunta dos instrumentos de integração almejados, conformando um grupo multidisciplinar composto por: referências técnicas do Vigiagua, da Vigilância Epidemiológica, da área de Meio Ambiente, da Educação em
Saúde e da Atenção Básica, integrantes dos distritos sanitários e da concessionária de abastecimento de água (COPASA), vereadores municipais, Secretários de Saúde e, também, das referências técnicas do Vigiagua vinculadas à Gerência Regional de Saúde e à Secretaria de Saúde do estado de Minas Gerais.

As informações coletadas nas entrevistas e reuniões com os informantes-chave (fase de avaliação) foram apresentadas, nos seminários centrais, pelos pesquisadores ao grupo com o auxílio de recursos visuais (data-show e cartazes). Posteriormente, o espaço foi aberto para discussão e os participantes, por meio de intervenções verbais e por escrito, puderam delinear as ações necessárias para o alcance da integração intradepartamental e intersetorial almejadas. Posteriormente, foram estimulados a elaborar em grupos os planos de ação, englobando objetivos, etapas a serem cumpridas e estratégias para alcançá-los, os atores e os departamentos responsáveis bem como os prazos para sua execução. Dessa maneira foi possível traçar as prioridades de ação objetivando a integração entre a saúde e a Vigilância em Saúde Ambiental relacionada à qualidade da água para consumo humano, de forma a potencializar o envolvimento dos outros departamentos abrangendo, também, os setores considerados, pelo grupo, como corresponsáveis pela saúde da população. Após a apresentação dos planos de ação por um representante de cada grupo, adequações foram discutidas entre os presentes na busca por um consenso por todo o grupo. Um cronograma de atuação foi então elaborado e a forma e a frequência para os momentos de avaliações do plano de ação pactuados. Ocorreu, assim, o que Barbier (2002, p. 118) refere como "contratualização", ou seja, uma espécie de contrato que define ações e papéis a serem desempenhados pelos participantes do processo.

Importante ressaltar que o acesso por esses participantes às informações geradas e pactuadas no seminário constituiu ponto crucial. De acordo com Thiollent (2008), estas devem estar disponibilizadas de modo adequado a uma fácil consulta por parte de qualquer participante. Foram, portanto, disponibilizadas em forma de um "quadro de ações", em que constavam a problemática, ou questão sobre a qual se desejava atuar, o objetivo que se buscava atingir, ação ou estratégia necessária para alcançá-lo, responsável pela ação e as formas de avaliação. Além de apresentado e discutido no seminário, uma ata contendo este "quadro de ações" foi encaminhada para o contato eletrônico dos participantes.

Para maior compreensão, o Quadro 1 ilustra uma das ações pactuadas no seminário central realizado no município de maior porte populacional.

Conhecer o desejo de se trabalhar de forma multidisciplinar e as modalidades de atuação a serem executadas no contexto de cada localidade, promovendo a democracia participativa 
Quadro 1 - Fragmento do quadro de ações pactuadas no seminário de integração, município de maior porte

\begin{tabular}{llll}
\hline \multicolumn{1}{c}{ Objetivo } & \multicolumn{1}{c}{ Ação } & \multicolumn{1}{c}{ Quem? } & \multicolumn{1}{c}{ Como avaliar? } \\
$\begin{array}{llll}\text { Espacializar as informações } & \text { Mapear os casos de diar- } & \text { Profissionais que atuam } & \text { Identificar se o mapa: a) possibilita compreender a dinâmica } \\
\text { do Vigiagua e da Vigilância } & \text { reia e as fontes alternativas } & \text { no Vigiagua e Vigilância } & \text { das doenças diarreicas e demais doenças de veiculação } \\
\text { Epidemiológica } & \text { de água na área x. } & \text { Epidemiológica } & \text { hídrica; b) facilita a visualização de uma provável correlação } \\
& & \text { Pesquisadores UFMG } & \text { com as formas de abastecimento. }\end{array}$ \\
\hline
\end{tabular}

UFMG: Universidade Federal de Minas Gerais.

(GREENWOOD; LEVIN, 2006), também constituíram objetivos desse espaço de comunicação, considerado por Kemmis (2001) uma forma de ação para encorajar, desenvolver e manter fóruns abertos de diálogo. O autor julga a formação desse locus de atuação um resultado mais importante que a resolução do problema em si. É neste espaço coletivo e democrático que os atores podem contrapor desejos e ideias com possibilidades reais de intervenção sobre as situações a serem enfrentadas, e partir para a elaboração do almejado plano de ação (WICKS; REASON, 2009).

No caso específico desta pesquisa-ação, no que se refere às ações pactuadas, identificou-se nos três municípios a necessidade de aprimoramento das notificações das doenças pelos profissionais de saúde, principalmente da atenção básica, ou seja, na ponta do serviço. A capacitação dos agentes comunitários de saúde e de endemias, bem como de médicos, enfermeiros e demais profissionais que atuam na área da saúde sobre a importância do Vigiagua e sua atuação no município e a importância da Monitorização das Doenças Diarreicas Agudas (MDDA), também foram considerados, pelos participantes, aspectos de grande relevância para o êxito do trabalho. Paralelamente, o uso de instrumentos de Sistema de Informação Geográfica (SIG) também foi apontado como primordial para a construção de instrumentos visando ao planejamento conjunto das diferentes vigilâncias. A reestruturação do Vigiagua indicada em dois dos municípios, a qual compreende contratação de mais funcionários, instituição da cultura de utilização dos dados para subsidiar ação do departamento, maior aporte de recursos financeiros, definição de indicadores para delinear o trabalho, também foi apontada como condicionante para a continuidade do trabalho, pelo fato de ser esse departamento o articulador do processo de planejamento integrado,

\section{Fase de ação}

A fase de ação ou de implementação dos instrumentos elaborados objetivou testar estratégias e suas implicações no contexto político de cada município. Parte dos registros sobre a situação em que se deseja intervir (fase exploratória) e, após discussões e acordos entre os participantes, gera pactos de ação (fase de planejamento), que, quando colocados em prática (fase de ação), são continuamente avaliados na fase subsequente, de avaliação. Esta etapa não prevê a participação direta da equipe de pesquisadores na execução do plano de ação (THIOLLENT, 2008). No entanto, foram realizadas reuniões periódicas com o intuito de acompanhar o trabalho e oferecer suporte, quando e se necessário - o que foi verificado com mais frequência nos municípios de maior e de menor portes.

O registro das ações (ou os porquês de sua não completude e até mesmo a ausência de atuação) constitui instrumento preciso para participantes e pesquisadores, pois, por meio deste, é possível avaliar de forma minuciosa o trabalho realizado, possibilitando, ainda, discutir reajustes e direcionamentos. Nesse sentido, um roteiro pré-elaborado auxiliou a realização de ciclos avaliativos, referentes à fase de ação, que aconteceram periodicamente e intercaladamente com o afastamento da equipe de pesquisa para que a ação pudesse ser efetivada pelo núcleo e seus colaboradores

Esses ciclos de avaliação foram realizados com o intuito de confrontar o que havia sido pactuado e o que havia sido, de fato, cumprido. Assim, a partir das discussões geradas nessas reuniões com o núcleo e os colaboradores abriam-se, novamente, espaços para a ação. Nesse contexto, o diário de campo e os registros em audiovisual das conversas revelaram-se instrumentos úteis, pois, a partir deles, os pesquisadores puderam refletir sobre assuntos discutidos em reuniões e encontros informais, identificar possíveis desvios da ação, questionar o que estava sendo realizado, pontuar medidas que foram acordadas após encontros com o núcleo da pesquisa, além de facilitar a redação das atas, encaminhadas periodicamente aos participantes. Outro instrumento interessante consistiu na elaboração de linhas do tempo, que objetivaram demonstrar linearmente o caminho (nem sempre tão linear) traçado. Ressalta-se, ainda, uso do correio eletrônico para realização de contato com o núcleo da pesquisa e os colaboradores, possibilitando o agendamento de reuniões, envio de atas, lembretes referentes aos encaminhamentos oriundos das reuniões e oficinas, objetivando o engajamento do grupo.

É preciso alertar que a fase de ação pode, por vezes, se estender por um período maior que o previsto. A experiência de atuação em três municípios diferentes permitiu aos pesquisadores identificar que planos de ação nem sempre encontram seus correspondentes na prática, sendo alguns dos entraves apresentados e discutidos na seção: desafios e possibilidades. 


\section{Fase de avaliação}

Etapa obrigatória e contínua no processo de pesquisa-ação, a fase de avaliação apresenta como objetivos principais verificar os resultados das ações no contexto organizacional da pesquisa e suas consequências a curto e médio prazo (KRAFTA et al., 2007). Traduz a necessidade de se conhecer o desenrolar das ações propostas no cotidiano do serviço focalizando os principais obstáculos e desafios encontrados para a sua sedimentação. Há, de acordo com Thiollent (2008), um considerável interesse dos pesquisadores no que diz respeito à prática dos atores da situação que, juntos, desvelam as condições da ação. Ao confrontar os objetivos almejados na fase principal (ou de planejamento) com a prática do serviço após a ação, é possível identificar os nós críticos e readequar e/ou reformular as propostas de intervenção. É possível, ainda, refletir sobre a não ação. Importante ressaltar que a fase de avaliação está intimamente relacionada à fase de ação sendo sua dissociação praticamente imperceptível.

Um dos instrumentos utilizados para avaliar juntamente com os atores-chave o processo de trabalho desencadeado após o seminário de planejamento foi um roteiro direcionado, apresentado no Quadro 2. Teve como objetivo contrastar as pactuações realizadas na fase de planejamento com as ações executadas dentro de um período de tempo estipulado.

No caso particular dessa pesquisa, definiu-se que as avaliações ocorreriam respectivamente, 2, 6 e 10 meses após a realização do primeiro seminário. Além de reuniões periódicas com o núcleo da pesquisa, objetivando avaliações conjuntas do trabalho desenvolvido, outros três seminários foram realizados em cada um dos municípios, envolvendo todos os colaboradores. Reason (2006) afirma que as questões práticas da pesquisa-ação são geralmente abordadas em ciclos de ação e reflexão, nos quais os resultados de cada ciclo, utilizados para contextualizar o momento, são confrontados com os planos e as intenções previamente estipulados. Assim, em todo encontro avaliativo os participantes eram incitados a realizar uma contextualização e uma confrontação a partir, respectivamente, das perguntas "Onde chegamos?" e "Onde gostaríamos de ter chegado?". Portanto, esses encontros

\section{Quadro 2 - Roteiro de avaliação}

1. Com base no quadro elaborado contendo os objetivos e propostas apresentados no seminário de integração cite quais ações vêm sendo atualmente desenvolvidas pelo serviço.

2. Atualmente, as ações pactuadas estão em prática? Se não, explique os motivos.

3. Como se deu a implementação das ações pactuadas? Quais setores e profissionais foram envolvidos? Existiram entraves para sua implementação? Quais? Comente.

4. Quais serão os próximos passos? Quais setores estarão envolvidos? Qual o prazo previsto para sua execução? seguiram uma mesma linha estrutural (ou desenho metodológico), composta por contextualização, confrontação entre as ações planejadas e alcançadas e avaliação.

A partir dessa avaliação em conjunto, novos passos e propostas, ou correções do percurso, bem como o cronograma para a sua execução, foram discutidos, gerando a referida espiral de etapas (Lewin, 1946/1948) que estimula o processo contínuo de execução, observação, avaliação e recondução. É plausível afirmar, portanto, que a fase de avaliação constitui o alicerce de todo o trabalho, uma vez que permite cotejar planos e ações, teoria e prática, ações e reações. Para além desses espaços, os momentos avaliativos também aconteceram em encontros pontuais e reuniões que não contaram com a participação de todos os envolvidos, uma vez que tinham como foco as ações que não remetiam ao coletivo, mas somente ao núcleo de pesquisa como, por exemplo, o levantamento de dados sobre soluções alternativas de abastecimento de água.

A observação participante complementou o processo avaliativo, permitindo contrastar as questões discutidas nos seminários e nos encontros pontuais com a forma de atuação e comprometimento dos envolvidos. A partir dos registros realizados nos diários de campo, foram pontuadas questões que também incitaram a reflexão por parte dos envolvidos na pesquisa-ação.

O cronograma de execução das fases da pesquisa-ação, bem como as técnicas utilizadas e o período para sua execução, é apresentado na Tabela 2.

\section{Desafios e possibilidades}

Por ser mais dialógico do que outros métodos de pesquisa, a pesquisa-ação pode parecer menos precisa e menos objetiva. No entanto, a discussão e a participação dos pesquisadores e dos colaboradores em diversas estruturas coletivas (seminários, grupos, oficinas etc.) não são em si próprias nocivas à objetividade (THIOLLENT, 2008). Para Barbier (2002), uma das maneiras de assegurar o rigor científico na pesquisa-ação permeia a coerência lógica empírica e política das interpretações propostas nos diferentes momentos. Assim, salientando-se a sua flexibilidade intrínseca, a formulação do método deve ser o mais transparente possível.

Entretanto, é justo salientar que a pesquisa-ação não pertence ao pesquisador, e, por esse motivo, não depende apenas da sua vontade de gerar resultados imediatos e eficientes. A criação de espaços democráticos, em si, requer tempo e disponibilidade consideráveis de ambas partes (REASON, 2006). É possível, no entanto, elencar fatores que influíram - positiva ou negativamente - no processo de transformar a ação, como, por exemplo, o tamanho do município, o número de profissionais engajados e seus respectivos interesses, as relações interpessoais e, ainda, as relações de poder existentes nos contextos a serem modificados. Na fase 
Tabela 2 - Fases da pesquisa-ação.

\begin{tabular}{|c|c|c|c|}
\hline Fase do estudo & Estratégias e técnicas utilizadas & Objetivos/metas & Período de execução \\
\hline Fase preliminar & $\begin{array}{l}\text { Seleção dos municípios, elaboração } \\
\text { do roteiro de entrevistas, correção e } \\
\text { adaptação do roteiro, submissão ao } \\
\text { comitê de ética em pesquisa. }\end{array}$ & $\begin{array}{l}\text { Identificar municípios elegíveis para a realização da } \\
\text { pesquisa. } \\
\text { Avaliar instrumento de pesquisa - o roteiro de entrevista. }\end{array}$ & $\begin{array}{l}\text { Outubro de } 2008 \text { a } \\
\text { fevereiro de } 2009 \text {. }\end{array}$ \\
\hline $\begin{array}{l}\text { Fase exploratória } \\
\text { (estudo de campo) }\end{array}$ & $\begin{array}{l}\text { Entrevistas, observação, reuniões, } \\
\text { análise do material }\end{array}$ & $\begin{array}{l}\text { Avaliar a situação do serviço de vigilância da qualidade } \\
\text { da água para consumo humano em cada município } \\
\text { quanto aos parâmetros: uso e aplicabilidade do } \\
\text { sistema de informação; cobertura do serviço, tempo- } \\
\text { ralidade, espacialidade e nível de desagregação dos } \\
\text { dados; grau de interatividade ou interlocução com } \\
\text { outros setores/departamentos da instância municipal, } \\
\text { em especial, com a Vigilância Epidemiológica. }\end{array}$ & $\begin{array}{l}\text { Fevereiro } 2009 \text { a } \\
\text { maio de } 2009 .\end{array}$ \\
\hline $\begin{array}{l}\text { Fase principal } \\
\text { (planejamento da ação) }\end{array}$ & $\begin{array}{l}\text { Seminários } \\
\text { Oficinas } \\
\text { Reuniões }\end{array}$ & $\begin{array}{l}\text { Socializar os resultados da fase exploratória. } \\
\text { Refletir e debater com os atores participantes as deman- } \\
\text { das para superar os nós críticos detectados; estabelecer } \\
\text { e pactuar ações para aprimoramento das ações de } \\
\text { vigilância da qualidade da água para consumo humano } \\
\text { e de vigilância epidemiológica no município, e para o } \\
\text { estabelecimento de canais de comunicação entre os } \\
\text { setores e departamentos envolvidos. }\end{array}$ & $\begin{array}{l}\text { Maio de } 2009 \text { a } \\
\text { setembro de } 2010 .\end{array}$ \\
\hline $\begin{array}{l}\text { Fase de ação: implementação } \\
\text { das ações propostas para } \\
\text { integração das Vigilâncias }\end{array}$ & $\begin{array}{l}\text { Seminários, Observação, } \\
\text { Reuniões e Oficinas }\end{array}$ & $\begin{array}{l}\text { Implantar as ações propostas e pactuadas na fase } \\
\text { principal visando a integração das vigilâncias. }\end{array}$ & $\begin{array}{l}\text { Junho de } 2009 \text { a } \\
\text { agosto de } 2010 \text {. }\end{array}$ \\
\hline $\begin{array}{l}\text { Fase de avaliação: observação } \\
\text { do funcionamento e ajustes }\end{array}$ & $\begin{array}{l}\text { Reuniões } \\
\text { Questionários } \\
\text { Observação }\end{array}$ & $\begin{array}{l}\text { Avaliar os principais resultados atingidos em cada } \\
\text { uma das etapas previstas e possibilitar replanejamento } \\
\text { quando necessário. }\end{array}$ & $\begin{array}{l}\text { Maio de } 2009 \text { a } \\
\text { junho de } 2011 .\end{array}$ \\
\hline
\end{tabular}

exploratória, a forma como o pesquisador abordou cada um dos participantes, a aceitação (ou não) de implementação do projeto, os desejos e o momento vivenciado por cada um dos colaboradores influenciaram sobremaneira no processo. Outro fator relevante identificado foi o grau de instrução dos entrevistados, que despontou como um dos fatores que mais influenciou na coleta dos dados e, consequentemente, na desenvoltura nos encontros promovidos, ora na exposição das ideias, ou na proposição de ações. Constatouse que mesmo com a adequação dos questionários, realizada após aplicação em dois projetos-piloto, o entendimento e fluidez das questões variaram conforme a escolaridade e/ou experiência dos informantes-chave. Os profissionais mais articulados ou mais experientes em sua área de atuação se sentiram mais à vontade para discutir as questões, facilitando a análise dos discursos e o traçamento dos objetivos, bem como a indicação de colaboradores e propostas de discussão para os seminários. Identificou-se que aqueles profissionais que, de certa forma, se sentiram avaliados pelos pesquisadores durante as entrevistas responderam às questões de forma lacônica evitando, assim, um debate, supostamente mais produtivo para o trabalho conjunto.

Reason (2006) se refere a esse risco de os colaboradores adotarem posturas defensivas frente ao novo, ao diferente. Nesse sentido, Thiollent (2008) alerta para o risco de o pesquisador não perceber as 'jogadas' argumentativas dos vários parceiros e assimilar o que é dito como simples e fiel expressão da 'realidade' ou 'verdade'. Entretanto, comprovou-se possível identificar aqueles discursos que focalizam os problemas/questões de forma muito idealizada uma vez que contradições vieram a ocorrer durante uma mesma entrevista ou por meio da observação participante, ao que Reason (2006) se refere como "os aspectos inicialmente amorfos e incipientes que vão se desvelando no decorrer do processo".

Portanto, reitera-se a necessidade de imersão na realidade que se pretende atuar, por meio de aproximações paulatinas para conhecimento da realidade investigada e estabelecimento de relações de confiança entre colaboradores e pesquisadores. No contexto dessa pesquisa-ação, foi preciso criar relações com o grupo de atores que foram ao encontro tanto do interesse da pesquisa como dos envolvidos estabelecendo, já no início do processo, "espaços de comunicação abertos para a interação", conforme enfatizam Wicks e Reason (2009). Traçando um paralelo com a nossa experiência, pode-se afirmar que os seminários, oficinas e reuniões constituíram espaços que propiciaram essa troca de informações, discussão e avaliação das possíveis ações de enfrentamento tornando possível estabelecer parcerias intersetoriais e multidisciplinares que, de alguma maneira, contribuíram para o êxito dos objetivos e metas traçados. A observação participante também constituiu momento propício para troca de ideias e informações, em um ambiente menos formal, potencializando uma relação de parceria entre os pesquisadores e os participantes da pesquisa-ação. 
O fato de a ação ser dinâmica no tempo e espaço implica que as formas de contribuição e propostas acordadas na fase de planejamento devem ser flexíveis, transformando os responsáveis pela ação em agentes críticos e avaliadores, uma vez que os enfoques necessários são moldados pelo contexto de atuação. No entanto, identificou-se nos municípios estudados que, não raro, as propostas de ação tenderam a se encerrar no núcleo diretamente interessado na mudança (núcleo da pesquisa). Reitera-se, assim, a importância da definição dos colaboradores para o bom andamento do trabalho, priorizando a participação de atores diretamente inseridos na prática do serviço e que podem contribuir com maior propriedade para as questões levantadas, de forma que o plano de ação seja o mais factível possível. Com efeito, observou-se que o trabalho com um número menor de colaboradores possibilitou uma atuação mais coesa e concisa e, potencialmente, mais efetiva.

Com o avanço das discussões foi possível perceber uma paulatina apropriação do processo (e sua valorização) pelos participantes - diretos e indiretos — da pesquisa. Constatou-se, por exemplo, que os atores que compuseram os núcleos da pesquisa nos municípios de grande e pequeno portes passaram a assumir a ação pactuada, vislumbrando caminhos para seu êxito e envolvendo, de maneira autônoma (ou seja, sem o "aval" dos pesquisadores), novos colaboradores. Identificou-se, a partir de mudanças na forma com que os atores se referiam ao processo, que esse despertamento decorreu do entendimento de que sua finalidade ou interesse maior remete ao serviço, e não à pesquisa executada.

Entretanto, foi possível destacar, em alguns momentos, a resistência para o trabalho impostas por aqueles profissionais, tanto membros do núcleo de pesquisa como colaboradores, que se julgaram desestimulados e desempoderados. Constatou-se que, por vezes, o andamento da pesquisa não seguiu o planejado, entremeando-se a momentos em que o desenrolamento das propostas não acontecia, geralmente devido às ações prioritárias das agendas municipais, como combate à dengue, epidemia de gripe suína, vacinação H1N1. Essa "não ação", conforme definido por Davis (2007), também consistiu, portanto, em resultado a ser avaliado pelos participantes e pesquisadores, uma vez que envolveu variáveis distintas - institucionais, profissionais, pessoais - que comprometeram os resultados almejados pela pesquisa.

Assim como as ações, as "não ações" foram discutidas e avaliadas pelo grupo, identificando-se justificativas para as barreiras impostas no contexto particular do município. Entre as justificativas foram elencadas a congestionada agenda de trabalho dos técnicos, recursos humanos, tecnológicos, físicos e financeiros insuficientes, a hierarquia municipal e o compromisso político (ou sua inexistência). Formas inovadoras de atuação também foram relatadas por alguns atores como possíveis geradoras de resistência, uma vez que barreiras institucionais e pessoais podem intervir neste momento de mudanças. Ademais, não se pode ignorar a existência de prazos que devem ser cumpridos pelos pesquisadores envolvidos em projetos, e que atendem datas-limite relacionadas a financiamentos ou prazos acadêmicos, e pelos próprios participantes, que precisam vislumbrar desfechos que estimulem a continuidade do processo de trabalho. Conforme apontado por um participante em um dos seminários realizados, "o tempo do município é diferente", justificando, assim, o prazo despendido para a implementação das ações pactuadas, relacionada à agenda interna do serviço, disponibilidade de participação ou imprevistos de qualquer ordem.

Por fim, e não menos importante, é preciso estar atento para o fato de o afastamento da equipe de pesquisa potencialmente implicar em postergação, ou mesmo no encerramento das ações pactuadas. Observou-se, mais claramente nos municípios de pequeno e médio portes que os períodos de afastamento da equipe de pesquisa pode ocasionar a restauração da prática anteriormente adotada pelos profissionais do serviço. Uma possível explicação para esse distanciamento do objeto pelos profissionais que, a priori, aceitam participar do processo de implementação de novos instrumentos e estratégias, talvez esteja relacionada ao fato de os pesquisadores atuarem como propulsores da ação pactuada, seja cobrando pela atuação, discutindo os desafios encontrados ou buscando novas formas de ação juntamente com os profissionais. A priorização de instrumentos de comunicação que habilitem a formação de coalizões, bem como de canais de comunicação permanentes mostrou-se necessária. Entretanto, é importante salientar que o uso de correio eletrônico como instrumento de contato não correspondeu à dinâmica de comunicação esperada, o que pode ser atribuído à falha do instrumento, ou mesmo à cultura de uso da ferramenta visto que pequena parte dos participantes interagiu com a equipe de pesquisa utilizando tal recurso.

\section{Considerações finais}

A experiência descrita permite constatar que a pesquisa-ação aponta para uma nova realidade, não presente anteriormente ao seu desenvolvimento, por meio de uma forma de interação que busca inovar. Constatamos que a proposta de implementação de novos instrumentos e estratégias de trabalho pode sim ser favorecida por esse método, que envolve os profissionais e demanda por seu comprometimento. O objeto de pesquisa passa, então, a pertencer ao grupo, e não mais ao pesquisador, que - por vezes - somente observa. Pode-se afirmar que o objetivo inicialmente almejado, de aprimorar e fortalecer as 
ações de vigilância da qualidade da água para consumo humano a partir de articulações entre os departamentos que constituem a Vigilância em Saúde e entre os diferentes setores que compõem o escopo organizacional na instância dos municípios, foi apenas parcialmente atingido. No entanto, o método propiciou avaliações ricas para se aprofundar nas reais questões que implicam dificuldades para se articularem departamentos e setores, questões institucionais e próprias do contexto de atuação que podem definir se determinada ação logrará êxito. Possibilita, ainda, levantar discussões pertinentes acerca dos processos de trabalho.
Em alguns momentos foi necessário instigar o profissional a sair de sua zona de conforto, o que geralmente esbarra em dificuldades. Mas, em contrapartida, a apropriação pelos sujeitos implicados no processo e o seu envolvimento, a criação de espaços inter e intrainstitucionais e intersetoriais, o estabelecimento de novas relações e a ampliação do conhecimento acerca do objeto trabalhado constituem possibilidades efetivadas pelo emprego da pesquisa-ação e que, possivelmente, gerará mudanças e possibilidades de interações para além do escopo e da duração da própria pesquisa realizada.

\section{Referências}

ABDALLA, M.F.B. (2005) A pesquisa-ação como instrumento de análise e avaliação da prática docente. Ensaio: Avaliação e Políticas Públicas em Educação, v. 13, n. 48, p. 383-400.

BARBIER, R. (2002) A pesquisa-ação. Lucie Didio (trad.). Brasília, Plano. 157 p.

CERATI, T.M.; LAZARINI, R.A.M. (2009) A pesquisa-ação em educação ambiental: uma experiência no entorno de uma unidade de conservação urbana. Ciência \& Educação (Bauru), v. 15, n. 2, p. 383-392

BAUER, M. W.; AARTS, B. (2006) A construção do corpus: um princípio para a coleta de dados qualitativos. In: BAUER, M.; GASKELL, G. (org.). Pesquisa qualitativa com texto, imagem e som: um manual prático. 5a. ed. Petrópolis, Vozes.

CHIMENDES, V.C.G.; MELLO, C.H.P.; PAIVA, A.P. (2008) Análise de modelo para projeto e desenvolvimento de serviços: uma pesquisaação em uma empresa de transporte rodoviário de passageiros. Gestão \& Produção, v. 15, n. 3, p. 491-505

DAVIS, J.M. (2007) Rethinking the architecture: an action researcher's resolution to writing and presenting their thesis. Action Research, v. 5, n. 2 , p. 181-196.

DUARTE, R. (2002) Pesquisa qualitativa: reflexões sobre o trabalho de campo. Cadernos de Pesquisa, n. 115, p. 139-154.

ENGEL, G.I. (2000) Pesquisa-ação. Educar, n. 16, p .181-191. Curitiba, Editora da UFPR.

GREENWOOD, D.J.; LEVIN, M. (2006) Reconstruindo as relações entre as universidades e a sociedade por meio da pesquisa-ação. In: DENZIN, N; LINCOLN, D. (org.) O planejamento da pesquisa qualitativa: teorias e abordagens. 2a. ed. Porto Alegre, Artmed. p. 91-113.

GRITTEM, L.; MEIER, M.J.; ZAGONEL, I.P.S. (2008) Pesquisa-ação: uma alternativa metodológica para pesquisa em enfermagem. Texto \& Contexto Enfermagem, v. 17, n. 4, p. 765-770.

HOGA, L.A.K.; REBERT, L.M. (2007) Pesquisa-ação como estratégia para desenvolver grupo de gestantes: a percepção dos participantes.
Revista da Escola de Enfermagem da USP, v. 41, n. 4, p. 559-566.

INSTITUTO BRASILEIRO DE GEOGRAFIA E ESTATÍSTICA (IBGE). IBGE Cidades@: Rio de Janeiro, 2012. Disponível em: < http://www.ibge.gov. br/cidadesat/topwindow.htm?1>. Acesso em: 11 de jul. 2012.

KEMMIS, S. Exploring the relevance of critical theory for action research: emancipatory action research in the footsteps of Jürgen Habermas. (2001) In: REASON, P; BRADBURY, H. Handbook of action research: participative inquiry and practice. London, SAGE. p. 91-102.

KRAFTA, L.; FREITAS, H.; MARTENS, C.D.P.; ANDRES, R. (2007) O método da pesquisa-ação: um estudo em uma empresa de coleta e análise de dados. Revista Quanti \& Quali. Disponível em: http://www. faccat.br/download/pdf/posgraduacao/profaberenice/09pesquisa_ acao_2009_3.pdf. Acesso em: 21 abr. 2009.

LEWIN, K. Action research and minority problems. (1946/1948) In: LEWIN, G.W. Resolving social conflicts. New York, Harper \& Row. p. 201-216.

MELLO, A.L.S.F.; MOYSÉS, S.T., MOYSÉS, S.J. (2010) A universidade promotora de saúde e as mudanças na formação profissional. Interface: Comunicação, Saúde, Educação. v. 14, n. 34, p .683-392.

MIGUEL, P.A.C. (2009) Pesquisa- ação como um meio para a cooperação entre a universidade e a empresa - fatores relevantes. Revista Ciências Exatas, v.15, n.2. Disponível em: http://periodicos.unitau.br/ojs-2.2/ index.php/exatas/article/view/855/65. Acesso em: 30 nov. 2012.

MINAYO, M.C.S.; SANCHES, O. (1993) Quantitativo-qualitativo: oposição ou complementaridade? Cadernos de Saúde Pública, v. 9, n. 3, p. 237-248.

MORIN, E. (2004) Pesquisa-ação integral e sistêmica: uma antropopedagogia renovada. Michel Thiollent (trad). Rio de Janeiro, DP\&A. 225 p.

PIMENTA, S.G. (2005) Pesquisa-ação crítico-colaborativa: construindo seu significado a partir de experiências com a formação docente. Educação e Pesquisa, v. 31, n. 3, p. 521-539. 
PROGRAMA DAS NAÇÕES UNIDAS PARA O DESENVOLVIMENTO (PNUD). Atlas do desenvolvimento humano no Brasil. Disponível em: <http://www.pnud.org.br/atlas/>. Acesso em: 11 jul. 2012.

REASON, P. (2006) Choice and quality in action research practice. Journal of Management Inquiry, p.187-203.

REIGADA, C.; TOZONI REIS, M.F.C. (2004) Educação ambiental para crianças no ambiente urbano: uma proposta de pesquisa-ação. Ciência \& Educação, v.10, n.2, p.149-159.
SISTEMA NACIONAL DE INFORMAÇÕES SOBRE SANEAMENTO (SNIS). (2009) Diagnóstico dos serviços de água e esgotos -2009. Brasília, MCIDADES; SNSA.

THIOLLENT, M. (2008) Metodologia da pesquisa-ação. 16a ed. São Paulo, Cortez. $132 \mathrm{p}$.

WICKS, P.G.; REASON, P. (2009) Initiating actions research: challenges and paradoxes of opening communicative space. Action Research, v. 7 , n. 3, p. 243-262. 